\title{
Influence of Whole Body X-irradiation on the Liver and Possible Protective Effect by the Compatible Solute Ectoine in a Mouse Model
}

\author{
Sarhan D. A. ${ }^{1}$, Shehata R. R. ${ }^{1}$, Kandil Y. I. ${ }^{2}$, Kotb M. A. ${ }^{3}$, El-Bassiouni E. A. ${ }^{1}$ \\ ${ }^{1}$ Department of Pharmacology, Medical Research Institute, Alexandria University, Alexandria, Egypt \\ ${ }^{2}$ Department of Biochemistry, Faculty of Pharmacy, Al-Azhar University, Cairo, Egypt \\ ${ }^{3}$ Department of Medical Biophysics, Medical Research Institute, Alexandria University, Alexandria, Egypt
}

Email address:

dr_dalia_1980@yahoo.com (Sarhan D. A.), rowaida_rs@yahoo.com (Shehata R. R.), kandil.yasser@gmail.com (Kandil Y. I.), metkotb45@gmail.com (Kotb M. A.), elbassiouni@hotmail.com (El-Bassiouni E. A.)

\section{To cite this article:}

Sarhan D. A., Shehata R. R., Kandil Y. I., Kotb M. A., El-Bassiouni E. A. Influence of Whole Body X-irradiation on the Liver and Possible Protective Effect by the Compatible Solute Ectoine in a Mouse Model. European Journal of Biophysics. Vol. 4, No. 3, 2016 , pp. 16-21. doi: 10.11648/j.ejb.20160403.11

Received: June 14, 2016; Accepted: June 27, 2016; Published: July 13, 2016

\begin{abstract}
Exposure of mammals to ionizing radiation leads to the development of a complex dose-dependent series of physiological and pathological changes. The present study was undertaken to investigate the effect of whole body $\mathrm{x}$-irradiation of male mice with a single w dose of $6 \mathrm{~Gy}$ on the levels of some cytokines and parameters of oxidative stress, after one and seven days, in the liver. The possible protective effect of the compatible solute ectoine, which is known to reduce cell stress effects on the molecular level, was evaluated. The x-irradiated mice showed elevated interleukins in the liver. The levels of both the pro-inflammatory (IL-1 $\beta$ and IL-6) and the anti-inflammatory (IL-10) interleukins reached several times the control value with quantitative differences. The disturbance by low-dose $\mathrm{x}$-irradiation also affected $\mathrm{PGE}_{2}$. Malondialdehyde, used as indication of oxidative stress, was elevated in the livers of $x$-irradiated mice. Although, there were no statistically significant differences in the results of total glutathione among the irradiated mice as compared to control values, there were differences among the values of the reduced and oxidized forms. The calculated redox potentials, showed some variations in the different groups, but were all within the values indicating that the cells are in the proliferative phase and far from the apoptotic phase. Treatment with ectoine modulated all the tested biochemical effects induced by $\mathrm{x}$-irradiation in the liver. All the tested parameters had a tendency to go back to near control values.
\end{abstract}

Keywords: Ionizing Radiation, Cytokines, Ectoine, Interleukins, Malondialdehyde, Redox Potentials

\section{Introduction}

X-rays represent a form of electromagnetic irradiation that may affect most exposed cells depending on the dose. This type of radiation was proposed to cause increased oxidative stress and higher levels of reactive oxygen species (ROS), either directly or through radiolysis of water [1]. Whenever the endogenous antioxidant mechanisms are not fully functional, oxidative damage to various molecules may ensue, including increased lipid and protein oxidation. this leads to interference with signaling cascades through regulation of protein activities. On the other hand, free radical signaling could be mediated by cytokines, the participation of which in cellular pathways is modulated by the redox status. The cytokine mediators of oxidative stress can alter redox equilibrium by affecting reduced/oxidized glutathione shuttling and recycling. This, by necessity, indicates alterations in the activity of the participating enzymes $[1,2]$.

The strategy of protection against cellular damage by deep x-irradiation may be built on restoring homeostasis of the disturbed biochemical pathways by affording protection to, and preventing damage of, essential macromolecules. The use of agents known to preserve membrane integrity and protect the folding and hydration of proteins would preserve the function of receptors and the activities of the 
different enzymes including those with antioxidant or DNA-repair properties. Compatible solutes are characterized by being effective stabilizers of biomolecules including proteins and nucleic acids as well as biomembranes [3]. These properties make them potential candidates for cellular protection. The compatible solute Ectoine, [(s)-2-methyl-1, 4, 5, 6-tetrahydropyrimidine-4carboxylic acid], is known to preserve and protect both hydration and folding of proteins and the structural organization of membranes [4]. Ectoine has been reported to protect the human skin epithelial cells against ultraviolet (UV) irradiation [5]. However, little is known about its efficacy in protection against ionizing or other forms of radiation. A better understanding of this area will enable its use more effectively for protection of vital internal organs against undesirable effects of radiation.

\section{Materials and Methods}

Production of high energy x-rays was effected by a medical linear accelerator, which is a dual photon energy linac (primus, Siemens, Medical System Inc, Concord, Ca, USA). The system uses an exposure rate of 180 centiGray per minute (cGy/min) [6]. In the present study, a dose rate of 200 monitor units (MU) was used. This results in a dose energy rate of $200 \mathrm{cGy} /$ minute. Accordingly, irradiation for three minutes gives a dose of $6 \mathrm{~Gy}$.

Thirty (30) male Swiss albino mice, weighing 20-22 g each, were used as the experimental animals. Mice were obtained from the animal house of the Medical Research Institute, Alexandria University and were kept under observation for one week prior to study with free access to food and water. All procedures were performed in accordance with regulations of the National Research Council's guide for the care and use of laboratory animals. Mice were divided into the following groups of 6 animals each:

Group 1: the animals served as negative controls.

Group 2: the animals received a single x-ray dose of $6 \mathrm{~Gy}$ by exposure in the linear accelerator for three minutes and were sacrificed after 24 hours.

Group 3: the animals were $\mathrm{x}$-irradiated by a single dose of 6 Gy by exposure for three minutes in the linear accelerator and were sacrificed after one week.

Animals in all 3 groups received daily intraperitoneal injections of $0.2 \mathrm{ml}$ saline.

Group 4: the animals were injected intraperitoneally with $200 \mathrm{mg} / \mathrm{kg}$ ecotine [7] and irradiated by a single low dose of 6 Gy then sacrificed after 24 hours.

Group 5: the animals were irradiated by a single dose of 6 Gy and received 7 daily doses of $200 \mathrm{mg}$ ectoine per $\mathrm{kg}$ body weight.

Animals were sacrificed at the end of both treatment periods by cervical dislocation. Each liver was quickly dissected, washed with ice-cold saline and kept at $-80^{\circ} \mathrm{C}$ until assayed for the following parameters:

The pro-inflammatory interleukin-1 $\beta$ (IL-1 $\beta$ ) and interleukin-6, (IL-6), and the anti-inflammatory interleukin-10 (IL-10) [8], as well as prostaglandin $\mathrm{E}_{2}$ $\left(\mathrm{PGE}_{2}\right)$ [9] were determined. Oxidative stress parameters; represented by malondialdehyde (MDA) [10], as well as reduced (GSH) and oxidized glutathione (GSSG) [11]. Total glutathione was calculated using the equation: $\mathrm{tGSH}=\mathrm{GSH}+2 \mathrm{GSSG}$ and results were used to calculate the redox potential [12].

All data were expressed as mean \pm standard deviation. Descriptive statistics were performed using Microsoft Excel 2010. All analyses and graphics were performed using GraphPad Prism 2007 (GraphPad Software, San Diego, CA, USA). Differences between means were assessed by one way analysis of variance (ANOVA) followed by Tukey's procedure and were considered statistically significant at $P<0.05$.

\section{Results}

Changes in liver cytokines as a result of whole body $\mathrm{x}$ irradiation and treatment with ectoine are presented in Table 1. Both of the pro-inflammatory cytokines, IL-1 and IL-6, increased in the liver one day and one week after irradiation. The levels of IL-1 were more than 3 times and 6 times the control value respectively. Administration of ectoine $(200 \mathrm{mg} / \mathrm{kg} /$ day $)$ affected the levels of IL-1 $\beta$ causing it to be $31.8 \%$ after one day and $74.6 \%$ after 7 days below irradiated levels [Fig. 1]. The effects of $\mathrm{x}$-rays on IL6 in the liver paralleled those of IL-1. After irradiation with 6 Gy there was a substantial increase to more than 8 -fold and 16-fold that of control after one day and 7 days respectively [Fig. 2]. Treatment of the irradiated mice with ectoine caused a significant decrease of $19.6 \%$ and $75.3 \%$ below the untreated group. However, the levels of IL- $1 \beta$ and IL-6, following treatment with ectoine were still significantly higher than control [Table 1].

The pattern of change in IL-10 in the liver was the same as seen with the other determined interleukins [Fig. 3]. After 6 Gy whole body $x$-irradiation the increases in IL-10 reached levels about 5.4 and 10.5 times that of control after one and 7 days respectively. Results of treatment with ectoine were also qualitatively similar to other interleukins, resulting in significant decreases of the mean IL-10 values below the untreated groups. Such decreases amounted to $18.6 \%$ for the one day group and $74.6 \%$ for the 7 day group.

The prostaglandin $\mathrm{E}_{2}$ concentrations in mouse liver changed in the irradiated and treated groups [Fig. 4]. Because of the low level in control animals, such changes were relatively very large. $\mathrm{PGE}_{2}$ increased significantly from 28fold after one day to near 46-fold the control value by the seventh day after exposure to the 6 Gy irradiation dose. Treatment with ectoine caused a significant decrease in $\mathrm{PGE}_{2}$ levels [Table 1]. Although such levels were still higher than control, they were significantly below the irradiated groups. With ectoine treatment the level of $\mathrm{PGE}_{2}$ went down to about $25 \%$ and to $14 \%$ of the $6 \mathrm{~Gy}$ irradiated animals after one day and 7 days respectively. 


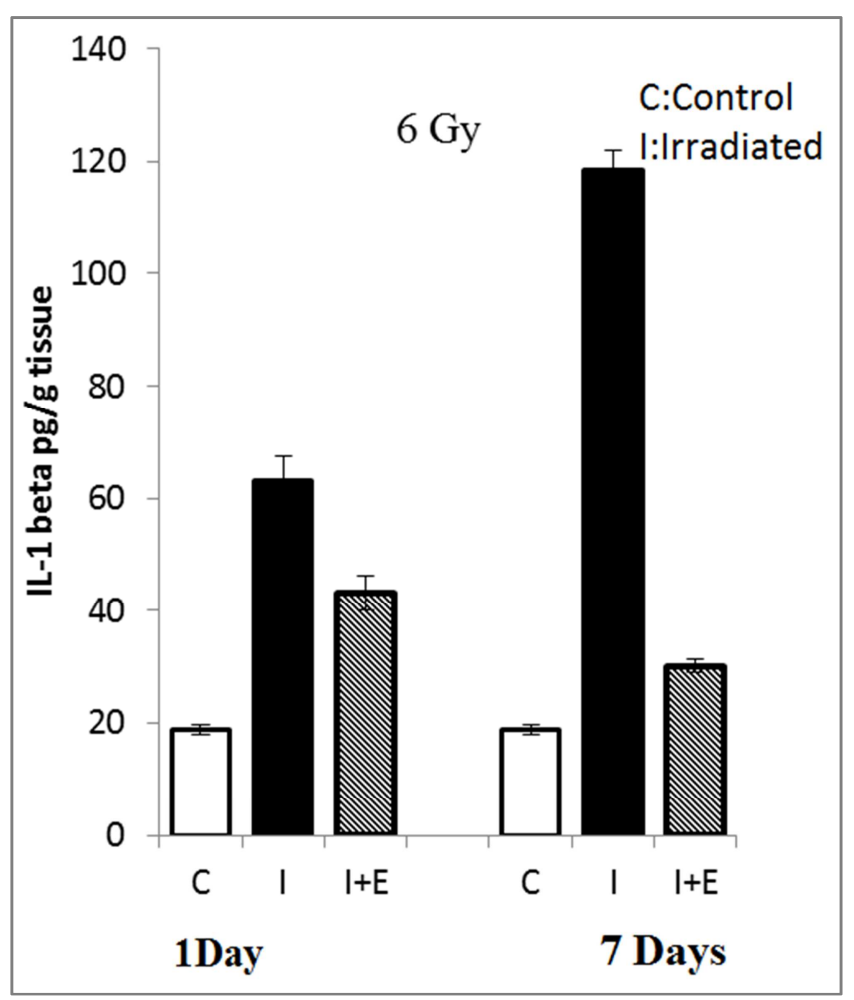

Figure 1. Changes in IL-1 $\beta$ in mouse liver after 1 day and 7 days of whole body X-irradiation with 6 Gy and treatment with ectoine (E).

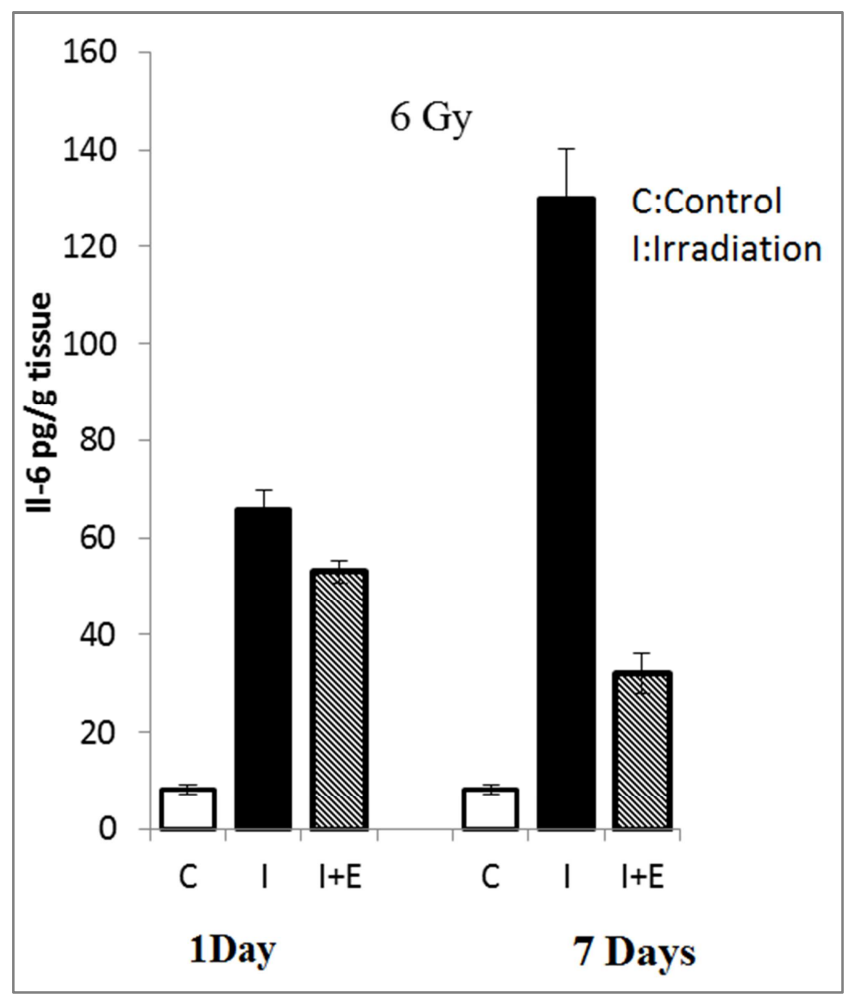

Figure 2. Changes in IL-6 in mouse liver after 1 day and 7 days of whole body X-irradiation with $6 \mathrm{~Gy}$ and treatment with ectoine (E).

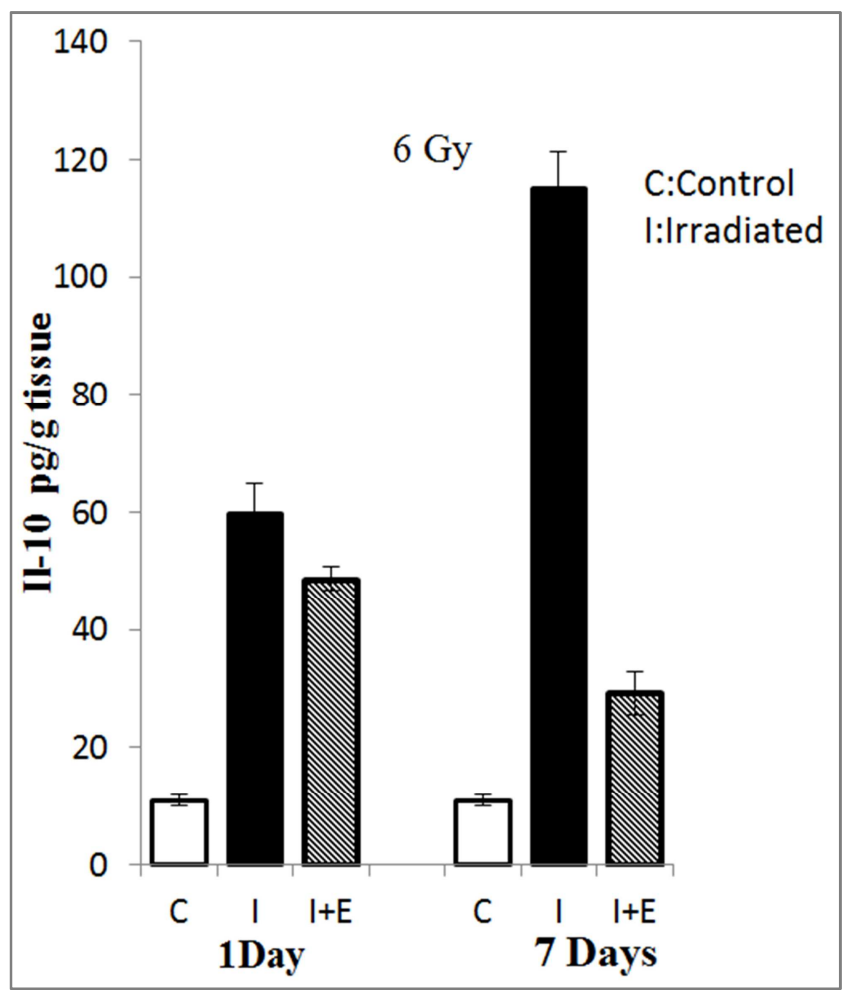

Figure 3. Changes in IL-10 in mouse liver after 1 day and 7 days of whole body X-irradiation with $6 \mathrm{~Gy}$ and treatment with ectoine $(E)$.

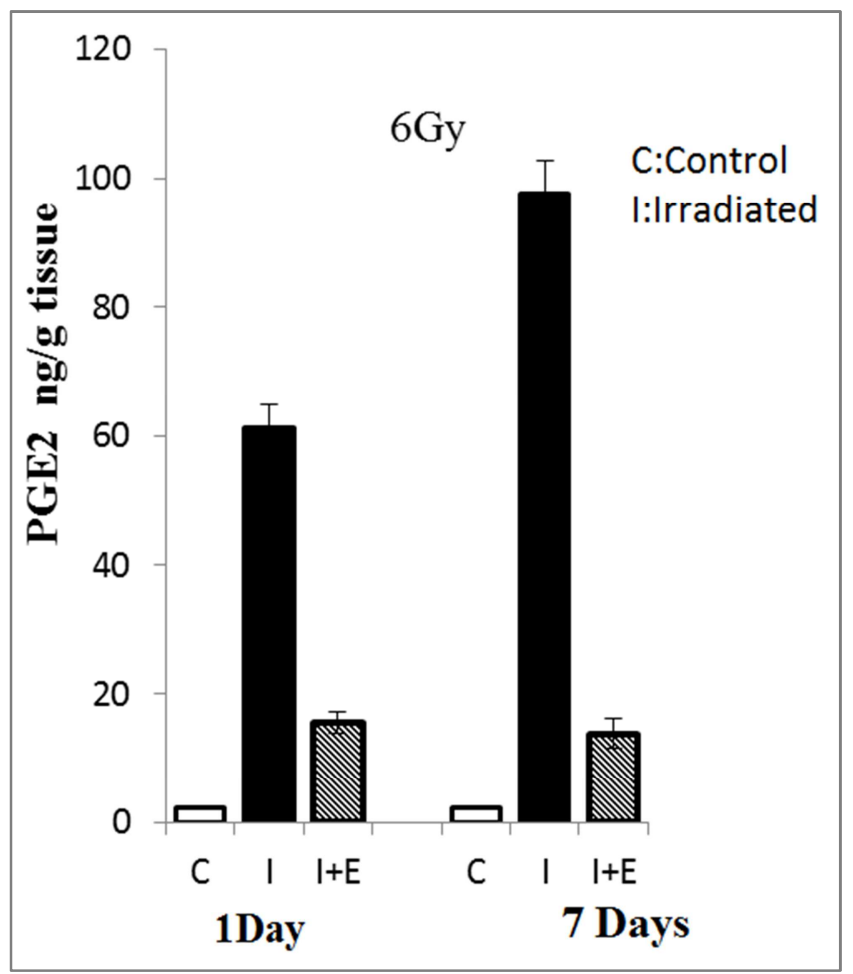

Figure 4. Changes in $P G E_{2}$ in mouse liver after 1 day and 7 days of whole body X-irradiation with $6 \mathrm{~Gy}$ and treatment with ectoine $(E)$. 
Table 1. Effect of 6 Gy whole-body $x$-irradiation and treatment with ectoine on cytokines in mouse liver.

\begin{tabular}{llllll}
\hline & \multirow{2}{*}{ Control } & 1 Day & & 7 Days & \\
\cline { 3 - 6 } & & Irradiated & Irradiated + Ectoine & Irradiated & Irradiated + Ectoine \\
\hline IL-1 $\beta(\mathrm{pg} / \mathrm{gm})$ & $18.7 \pm 0.84$ & $63.2 \pm 4.41^{*}$ & $43.1 \pm 3.0^{* \#}$ & $118 \pm 3.36^{*} \#$ & $30.1 \pm 1.11^{* \dagger}$ \\
IL-6 $(\mathrm{pg} / \mathrm{gm})$ & $8.11 \pm 1.0$ & $65.9 \pm 3.97^{*}$ & $53.0 \pm 2.27^{* \#}$ & $130 \pm 10.2^{*} \#$ & $32.1 \pm 4.14^{*} \dagger$ \\
IL-10 $(\mathrm{pg} / \mathrm{gm})$ & $11.0 \pm 1.0$ & $59.8 \pm 5.06^{*}$ & $48.6 \pm 2.03^{*}$ & $115 \pm 6.35^{* *}$ & $29.2 \pm 3.70^{* \dagger}$ \\
PGE-2 $(\mathrm{ng} / \mathrm{gm})$ & $2.13 \pm 0.23$ & $61.1 \pm 4.95^{*}$ & $15.5 \pm 1.72^{* \#}$ & $98.7 \pm 5.41^{* \#}$ & $13.9 \pm 2.12^{*} \dagger$ \\
\hline
\end{tabular}

* Significantly different from control group

\# Significantly different from 1 Day irradiated group

$\uparrow$ Significantly different from 7 Day irradiated group

Malondialdehyde, the principal product in lipid peroxidation, is used as indicator of oxidative stress. Because of the initial low levels in the control group, the magnitude of changes in the irradiated groups were apparently large. After one day and 7 days, the level was 3.6- and 5.3-times the control value.

The effect of low-dose x-irradiation on glutathione was not as strong as may be expected. There were no statistically significant differences in the results of total glutathione among all the groups of mice tested [Table 2]. However, there were differences among the values of the reduced and oxidized forms. X-irradiation caused decreases in reduced glutathione $(\mathrm{GSH})$. The 6 Gy dose resulted in a mean decrease of $7.4 \%$ below that of control after one day reaching $14.1 \%$ less than control by day 7 . Administration of ectoine caused a correction of the reduced glutathione level, as it caused an increase of $8.3 \%$ after one day. Such beneficial effect was higher with the longer treatment duration group, as the level was elevated by $11.8 \%$. The oxidative stress resulting from whole body $\mathrm{x}$-irradiation was also reflected in the increased oxidation of glutathione. The oxidized form of glutathione (GSSG) reached $48 \%$ above control after one day. The 6 Gy dose gave a stronger effect after 7 days, as the GSSG level increased by $64 \%$. The beneficial effect of ectoine extended to the oxidized form of glutathione. Decreases in the levels of GSSG in the treated mice below the irradiated animals were found to be of $16.2 \%$ and $14.6 \%$ respectively. The values of the calculated redox potentials indicated that the liver cells were well in the reduced environment within the range of the proliferative state.

Table 2. Effect of whole-body x-irradiation and treatment with ectoine on oxidative stress markers in mouse liver.

\begin{tabular}{llllll}
\hline & \multirow{2}{*}{ Control } & 1 Day & & 7 Days & \\
\cline { 2 - 6 } & & Irradiated & Irradiated + Ectoine & Irradiated & Irradiated + Ectoine \\
\hline MDA $(\mathrm{nmol} / \mathrm{gm})$ & $13.2 \pm 2.19$ & $47.10 \pm 3.61^{*}$ & $37.20 \pm 4.13^{*} \#$ & $52.10 \pm 3.68^{*}$ & $40.50 \pm 3.88^{*} \dagger$ \\
GSH $(\mu \mathrm{mol} / \mathrm{gm})$ & $4.05 \pm 0.51$ & $3.75 \pm 0.45$ & $4.06 \pm 0.35$ & $3.48 \pm 0.69$ & $3.89 \pm 0.56$ \\
GSSG $(\mu \mathrm{mol} / \mathrm{gm})$ & $2.40 \pm 0.24$ & $5.58 \pm 0.99^{*}$ & $4.02 \pm 0.59^{* \#}$ & $6.03 \pm 0.61^{*}$ & $3.61 \pm 0.71^{* \dagger}$ \\
Total glutathione & $8.87 \pm 0.86$ & $14.9 \pm 2.12$ & $12.1 \pm 1.13$ & $15.5 \pm 0.82$ & $11.1 \pm 1.75$ \\
$(\mu \mathrm{mol} / \mathrm{gm})$ & $265 \pm 2.88$ & $252 \pm 3.46^{*}$ & $258 \pm 3.87 \#$ & $248 \pm 6.53^{*}$ & $259 \pm 3.08 \dagger$ \\
Redox potential $(-\mathrm{mV})$ & 268
\end{tabular}

* Significantly different from control group

\# Significantly different from 1 Day irradiated group

$\uparrow$ Significantly different from 7 Days irradiated group

\section{Discussion}

The exposure of mammals to ionizing radiation leads to the development of a complex dose-dependent series of physiological and pathological changes [13]. Opposing hypotheses on the potential risks of low-dose radiations have been advanced. One hypothesis proposes that there is no dose of radiation that can be considered completely safe and that the use of radiation must always be determined on the basis of risk and benefit. Another hypothesis suggests that the health risks of diagnostic doses less than 10 Gy are not measurable [14].

Data from the present study showed that low level $\mathrm{x}$ irradiation caused elevation of cytokines in the liver. The liver has been reported to be a highly radiosensitive hematopoietic organ. It is the primary organ responsible for detoxifying damaging electrophiles generated during oxidative stress $[15,16]$. The reported effects of cytokines in case of irradiation are conflicting. Several possible mechanisms for radioprotection have emerged including reduction of oxidation damage and apoptosis. In contrast, sensitizing mechanisms may include increased oxidative damage, which may occur in absence of scavenger induction, as well as enhanced apoptosis [17].

Cytokine measurements in tissue or in the peripheral circulation have been an important part of the process of defining the role various cytokines play in health and disease. It has been suggested that local cytokine levels and activity are of considerably greater value for monitoring of pathological events in a target tissue than are systemic serum cytokine levels [18]. In the present study, the x-irradiated mice showed elevated interleukins in the liver. The increases in the concentration of IL-1 $\beta$ were accompanied by concomitant increases in IL-6. Interleukin-1 $\beta$ has been reported to induce IL-6 [19], which can mimic many of its actions [20]. The intracellular increase in the level of IL-1 is 
followed rapidly by induction of several biochemical events [21], including induction of the transcription of COX-2. Once triggered, COX-2 production is elevated and large amounts of $\mathrm{PGE}_{2}$ are produced in cells stimulated with IL-1. Therefore, many of the biological activities of IL-1 are proposed to be due to increased $\mathrm{PGE}_{2}$ production [22].

It may be noted that the increases of the pro-inflammatory cytokines, in the present study, were also accompanied by significant increases in the anti-inflammatory IL-10. Probably such increase may represent a defense mechanism against the high levels of IL-1 $\beta$ and other pro-inflammatory mediators caused by irradiation. It is generally recognized that counteraction of the inflammatory response to radiation is important to attenuate acute radiation effects and prevent consequences [23]. It has been proposed that the biological activities of IL-10 in modulating inflammation in this case may be caused, in part, by down-regulation of proinflammatory cytokines and the expression of their receptors and up-regulation of cytokine inhibitors [24]. The downregulation of IL- 6 by IL-10 has been shown and it has been proposed that limiting one step of the inflammatory process cascade might control the progression of the inflammatory reactions. This can be of benefit since it has been widely shown that the inflammatory reaction is intrinsically destructive for surrounding tissues. In addition an early release of cytokines could be responsible for the damage leading to the hypothesis of perpetual cascade of cytokines initiating radiation-induced late effects [25].

Prostaglandin $\mathrm{E}_{2}$ was found, in the present study, to increase following wirradiation as previously reported [26]. A broad spectrum of mediators regulates the expression of COX-2. Whereas pro-inflammatory cytokines such as IL-1 $\beta$ and IL-6, among other factors, induce COX-2, the antiinflammatory cytokine IL-10 inhibits the expression of this enzyme [27, 28]. Therefore, it seems that the balance between the effects of pro-inflammatory and antiinflammatory cytokines may determine the short-term or long-term outcome of irradiation effects.

The data obtained in the present work point out to the stronger effect of the low dose $x$-irradiation on interleukins and prostaglandin $\mathrm{E}_{2}$ than on oxidative stress as measured by changes in MDA as well as different forms of glutathione and the calculated redox potential. The effect of low-dose $\mathrm{x}$ irradiation on glutathione was not as strong as may be expected. There were no statistically significant differences in the results of total glutathione among all the groups of mice as compared to control values. However, there were significant differences among the values of the reduced and oxidized glutathione. Because of the relatively small initial levels in the control group, the percentage changes in the irradiated groups were apparently large.

Current concepts of the mechanism of action of reactive oxygen species (ROS) include alteration in intracellular redox state and oxidative modification of proteins. Cellular cytosol is normally maintained under strong reducing conditions, which is accomplished by the action of intracellular redox-buffering systems [29]. This could be reflected in the calculated values of redox potential, which showed some variations in the different groups, but they were all within the values indicating that the cells are in the proliferative phase and far from the apoptotic phase [12].

The seven consecutive doses of ectoine, given over one week, gave better results causing all tested biochemical parameters to go back to near normal values. If the main effect of radiation is on protein [30] and the key to cell survival is through conserving the integrity of the antioxidant enzymes [31, 32] then compounds known to possess such properties would be good candidates for the protective action. Compatible solutes, including ectoine, are characterized by being effective stabilizers of biomolecules including proteins and nucleic acids as well as biomembranes [3]. It was shown that ectoine increased the hydration of a model biological membrane resulting in higher membrane fluidity [4]. This may lead to interference with membranecoupled pro-inflammatory signaling. The effect of ectoine on the inflammatory process was previously investigated and it was suggested that this compatible solute probably has antiinflammatory properties [3].

Results of the present study demonstrated that the 6Gy whole-body irradiation caused a significant increase in the MDA level, whereas the antioxidant levels of reduced glutathione were decreased in the livers of irradiated mice. Administration of ectoine effectively decreased MDA levels in the livers of all irradiated animals. Reduced glutathione, as an antioxidant, has been considered as the most accurate single indicator of cell health, as its depletion represents vulnerability to oxidant attack [33]. The significantly elevated levels of reduced glutathione may be a factor responsible for the inhibition of MDA generated from lipid peroxidation. In addition, the significant increase in GSH protects cellular proteins against oxidative damage through the glutathione redox cycle and also directly detoxifies ROS induced by irradiation.

\section{Conclusion}

Protection of biological systems from ionizing radiation is of paramount importance in planned as well as unplanned accidental exposures to radiation. Development of effective agents to combat radiation damages using nontoxic radio protectors is of considerable interest in health care, particularly in radio diagnostics and therapy. Despite the lack of clinical data, results of the present study suggest that ectoine has the potential to protect tissues from radiation injury and should be considered as a candidate for further development as a radiation injury countermeasure.

\section{References}

[1] Spitz DR, Azzam EI, Li JJ, Glus D. Metabolic oxidation/reduction reactions and cellular responses to ionizing radiation: a unifying concept in stress response biology. Cancer Metastasis Rev 2004; 23: 311-22. 
[2] Chen CY, Huang YL, Lin TH. Association between oxidative stress and cytokine production in nickel-treated rats. Arch Biochem Biophys. 1998; 356: 127-132.

[3] Buommino E, Schiraldi C, Baroni A, Paoletti I, Lamberti M, De Rosa M, Tufano MA. Ectoine from halophilic microorganisms induces the expression of hsp 70 and hsp 70 $\mathrm{B}$ in human keratinocytes modulating the proinflammatory response. Cell Stren Chaperons 2005; 10: 197-203.

[4] Harishchandra RK, Wulff S, Lentzen G, Neuhaus T, Calla HJ. The effect of compatible solute Ectoine on the structural organization of lipid monolayer and bilayer membranes. Biophys Chem 2010; 150: 37-46.

[5] Buenger J, Driller H. Ectoin: an effective natural substance to prevent UVA-induced premature photoaging. Skin Pharmacol Physio 2004; l 17: 232-7.

[6] Coia LR, Moylan DJ. Introduction to clinical radiation oncology. $3^{\text {rd }}$ ed, Medical Physics Pub, Madison, Wisconsin 1988.

[7] Abdel-Aziz H, Wadie W, Abdallah DM, Lenzen G, Khayyal MT. Novel effects of Ectoine, a bacteria-derived natural tetrahydro pyremidine, in experimental colitis. Phytomed 2013; 20: 585-9.

[8] Rosa MS, Pinto AM. Cytokines. In: Burtis CA, Ashwood ER, Bruns DE (eds). Tietz textbook of clinical chemistry and molecular diagnostics. $4^{\text {th }}$ ed. St Louis: Elsevier Saunders; 2006. 645-744.

[9] Burtis CA, Ashwood ER. Lipids, lipoproteins, apolipoproteins and others cardiovascular risk factors, prostaglandins. In: Bruns DE (eds). Tietz textbook of clinical chemistry and molecular diagnostics. $6^{\text {th }}$ ed. St Louis: Elsevier Saunders; 2008. 409-11.

[10] Ohkawa H, Ohishi N, Yagi K. Assay for lipid peroxides in animal tissues by thiobarbituric acid reaction. Anal Biochem 1979; 95: 351-8.

[11] Griffith OW. Determination of glutathione and glutathione disulfide using glutathione reductase and 2-vinyl pyridine. Anal Biochem 1980; 106: 207-12.

[12] Schaffer FQ, Buettner GR. Redox environment of the cell as viewed through the redox state of glutathione disulfide/glutathione couple. Free Radic Biol Med 2001; 30: 1191-1212.

[13] Song JY, Han SK, Bae KG, Lim DS, Son SJ, Jung IS, Yi SY, Yun YS. Radioprotective effects of ginsan, an immunomodulator. Radiat Res 2003; 59 (6): 768-74.

[14] Hogatt J, Singh P, Stilger KN, Plett PA, Sampson CH, Chua HL, Orschell CM, Pelus LM. Recovery from hematopoietic injury by modulating prostaglandin $\mathrm{E}_{2}$ signaling postirradiation. Blood Cells Mol Dis 2013; 50: 147-53.

[15] Pratheeshkumar P, Kuttan G. Protective role of Vernonia cinerea L. against gamma radiation-induced immunosupressio and oxidative stress in mice. Hum Exp Toxicol 2011; 30: 1022-38.

[16] Devasagayam TPA. Protective effect of an aminothiazole compound against $\gamma$-radiation induced oxidative damage. Free Radic Res 2011; 45: 1342-53.

[17] Neta R., Modulation with cytokines of radiation injury: suggested mechanism of action. Environ Health Perspect. 1997; 105: 1463-1465.
[18] Mathey E, Pollard J, Armati P. In situ hybridization for cytokines in human tissue biopsies. Methods Mol Biol 2003; 204: $57-66$

[19] McIntosh JK, Jablons DM, Mule JJ, Nordan RP, Rudikoff S, Lotze MT, Rosenberg SA. In vivo induction of IL-6 by administration of exogenous cytokines and detection of de novo serum levels of IL-6 in tumor-bearing mice. J Immunol 1989; 143: 162-7.

[20] Neta R, Perlstein R, Vogel SN, Ledney GD, Abrams J. Role of interleukin-6 (IL-6) in protection from lethal irradiation and in endocrine response to IL-1 and tumor necrosis factor. $J$ Exp Med 1992; 175: 689-94.

[21] O'Neill LAJ. Toward an understanding of the signal transduction pathways for interleukin-1. Biochem Biophys Acta 1995; 1266: 31-44.

[22] Dinarello CA, Interleukin-1 $\beta$, a proinflammatory cytokine. Eur Cytokine Netw 2000; 11 (3): 483-6.

[23] Michalowski AS. On radiation damage to be normal tissues and its treatment. II. Anti-inflammatory drugs. Acta Oncologica 1994; 33 (2): 139-57.

[24] Glocker EO, Kotlart D, Klein C, Shah N, Grimmbacher B. IL10 and IL-10 receptor defects in humans. Ann N Y Acad Sci 2011; 1246: 102-7.

[25] Rubin P, Johnson CJ, McDonald S, Finkelstein JN. A perpetual cascade of cytokines postirradiation leads to pulmonary fibrosis. Int J Radiat Oncol Biol Phys 1995; 33: 99-109.

[26] Eisen V, Walker DI. Effect of ionizing radiation on prostaglandin-like activity in tissues. Br J Pharmacol 1976; 57: $527-32$.

[27] Nirra H, Otzuka T, Izuhara K, Yamaoka K, Ohshima K, Tanabe T, Hara S, Nemoto Y, Tanaka Y, Nakashima H, Niho Y. Regulation by interleukin-10 and interleukin-4 of cyclooxygenase expression in human neutrophils. Blood 1997; 89: $1621-8$

[28] Henze B, Brune K. Cyclooxygenase-2: 10 years later. $J$ Pharmacol Exper Therap 2002; 300 (2): 367-75.

[29] Thannickal VJ, Fanburg BL. Reactive oxygen species in cell signaling. Am J Phjysiol, Lung Cell Mol Physiol 2000; 279: L 1005- 28 .

[30] Anno GH, Baum SJ, Withers MR, Young RW. Symptomatology of acute radiation effect in humans after exposure to doses 0.5-30 Gy. Health Phys 1989; 56: 821-38.

[31] Robinson CK, Webb K, Kaur A, Jaruga P, Dizaroglu M, Baliga NS Place A, Diruggiero J. A major role for nonenzymatic antioxidant processes in radioresistance of Halobacterium salinarum. J Bacteriol 2011; 193: 1653-62.

[32] Zhao W, Robbins ME. Inflammation and chronic oxidative stress in radiation-induced late normal tissue injury: therapeutic implications. Curr Med Chem 2009; 16: 130-43.

[33] Bump EA, Brown JM. Role of glutathione in the radiation response of mammalian cells in vitro and in vivo. Pharmacol Ther 1990; 47: 117-36.

[34] Adaramoye OA, Popoola BO, Farombi EO. Effects of Xylopia aethiopica (Ammonaceae) fruit methanol extract on $\gamma$ radiation-induced oxidative stress in brain of adult male Wistar rats. Acta Biol Hung 2010; 61: 250-61. 